\title{
A Comparison of Two Methods of Library Instruction for Students in Introductory Biology
}

\begin{abstract}
What should be taught in a library instruction program for general biology students is presented and two ways of providing the instruction are discussed. The two methods, lecture-demonstration and guided exercise (form of programmed instruction), are described, and evaluated for their effectiveness. The evaluations considered are students' ability to collect a satisfactory bibliography, scores on two objective exams on library skills, and students' attitudes toward the library instruction program. It is concluded that neither method is superior, although the guided exercise continues to be used, for the reasons given. Improvements in the program are suggested.
\end{abstract}

L portant component in the education of today's undergraduate students. There is not only a definite trend toward more undergraduate independent study but also a growing need for continued learning in years beyond one's formal education. ${ }^{1,2}$ Without library skills, a person is likely to use and reuse only a minimum number of library resources. While fundamental instruction in the use of the card catalog, Readers' Guide, and other basic reference and indexing tools is essential, it is important that colleges and universities go beyond this and develop in students a more sophisticated understanding of the library. ${ }^{3}$

To be effective, instruction in the use of the library needs to be an integral and fundamental part of the course work. Course assignments should be designed to get students to use patterns of behavior felt to be desirable in efficient

Mr. Kirk is the science librarian, Earlham College, Richmond, Indiana. use of the library. ${ }^{4}$ Here a great deal of responsibility rests with the faculty because:

If he (the student) can successfully complete the academic program by reading the text, attending lectures, and passing an examination based on text and lecture, there is little stimulus for him to build competence in research or research tools. ${ }^{5}$

This library instruction beyond the introductory level should provide an opportunity for the student to carry out the actual steps of a library search. In fact, the study described here attempts to measure the effectiveness of a library instruction technique designed to have students learn by doing. The study was carried out at Earlham College using a class of approximately 190 students in a general biology class which the students took as part of their general distribution requirement in science.

\section{Content of the Library Instruction}

In planning any program of library 
instruction, it is necessary to develop a list of the skills and knowledge to be taught. The following list describes the information which the faculty and librarian thought to be important for the students of the Introductory Biology course. This list was developed out of our experience with the scientific literature and several years' observations of the ways in which undergraduates can make the most effective use of this literature.

I. General types of reference books and some specific examples

A. Encyclopedias: e.g., McGrawHill Encyclopedia of Science and Technology, revised edition, 1966.

B. Dictionaries: e.g., Gray, Dictionary of the Biological Sciences, 1967, and King, Dictionary of Genetics, 1968.

C. Monographs

D. Serials

1. Periodicals

2. Annual reviews

E. Bibliographies

II. Periodical indexes and scientific abstracting services

A. Biological Abstracts, its organization, how to use the author and key word indexes.

B. Science Citation Index, its uniqueness, how to use it.

III. The Library Card Catalog. The importance of using the subject heading list (Library of Congress List of Subject Headings Used in the Dictionary Catalog, 7th ed., 1966) is to be emphasized. This includes recognition and meaning of the see, see also to, and see also from references in the subject heading list. Also to be included is the use of subject heading tracings found on the author card of a book known by the student, as a method of selecting subject headings.

IV. A general understanding of the or- ganization of scholarly scientific literature and the relationships among the various types

A. Journal and report literature (Primary). The backbone of science or biology. The reports of original research.

B. Journals, monographs, reviews, and review series (Secondary literature). The synthesis and surveys of science.

C. Handbooks, dictionaries, encyclopedias, texts (Tertiary literature). Literature intended for a specific purpose, which presents only specific information, data, or definitions. In addition, literature intended as instructional material, especially literature designed to provide a broad survey of a field for the beginner. This material is based on secondary sources.

V. Search strategy. While most of the items listed above are concerned primarily with knowledge to be learned, this item (and VI) involves the activities and routines comprising search strategy. It requires knowledge of the basic search strategy: the initial use of encyclopedias and texts, followed by location of monographs and reviews, and finally a search of the periodical indexes. It also requires recognition of where to start the process with an individual search. In addition, students should recognize when a search step is no longer useful, when to retrace a step, and when to skip a step. One of the undefinable and unmeasurable aspects is the development of a personal method of search and the confidence to use it efficiently.

VI. The analysis of a subject so that the proper questions might be asked of the literature. This is perhaps the most difficult of skills to teach. This analysis is seen to include in part 
the answers to the following questions.
A. What is the subject? Its content? What fields are related to it?
B. Is the bulk of information in the field newly discovered or has it been well known for a number of years?

C. What are the controversial aspects or the major questions of disagreement settled at present?

D. Who are the important scientists who have contributed to the subject?

E. Do certain organisms predominate as the objects of study for the subject of interest? (For example: Drosophila in genetics; Planaria in chemical learning)

F. How is the subject expressed by authorities in the field? Is the terminology confusing? Synonyms?

\section{Method OF LibraRy Instruction}

On the basis of the registration figures for the enrollment in the Introductory Biology Laboratory sections, two groups were formed for the purpose of comparing two methods of library instruction. The students had been tested on library skills learned in high school and no significant difference was found between the two groups. Both groups were then given library instruction during the first full week of classes. The instruction consisted of either a twohour lecture demonstration by the librarian or a guided exercise done by the students individually at their own speed in the library. Identical information was presented in both forms of instruction.

\section{The Lecture-Demonstration}

The lecture-demonstration was a twohour presentation covering the essentials of the search strategy plus the me- chanics of using the reference tools and card catalog. The reference tools were presented in the same order they were likely to be used when carrying out a search. Transparencies were used to illustrate pages from the reference tools.

The students who received the lecture-demonstration were assigned the following readings to be completed before they came to the lecture session.

1. "Bibliography of Basic Reference Sources." This is an annotated bibliography, which the librarians had prepared, of the most important encyclopedias, dictionaries, bibliographies, and periodical indexes the students were likely to use. Annotations briefly described the titles, their functions, and pointed out their limitations.

2. "The Card Catalog." This is a brief discussion of the card catalog designed primarily to introduce the students to guide cards and check tracings in the subject half of the card catalog.

3. "Guide to Science Citation Index." A folder on how to use the S.C.I. published by the Institute for Scientific Information.

4. "Literature of Science and Technology." McGraw-Hill Encyclopedia of Science and Technology, 2d ed., v. 7, p.242a-242f. McGraw-Hill, 1966.

5. Bottle, Robert. The Use of Biological Literature, p.9-13, 35-40, 53-57.

\section{The Guided Exercise}

This was the experimental method and was designed to guide the student through an actual library search on a particular problem. By doing this, we hoped to show him and have him experience using the methods considered appropriate for library research. This educational tool, called here the guided exercise, is a cousin to the programmed instruction technique which has proven so useful in recent years. However, the guided exercise depends on more than just going through printed frames at 
one's place of study. It requires the student to go to the library and actually carry out a series of steps which encompass an appropriate search strategy as outlined earlier. Sample pages from the exercise follow.

\section{Sample Pages from Section 1 of THE GUIDED EXERCISE}

Page 30

1. Mollusca (phylum)

2. Cephalopoda (class)

3. Octopodida (order)

4. Invertebrates

5. Nervous system

6. Visual discrimination-visual search

7. Octopus

Referring back to the list of key words developed in 29 will give us a complete list of key words to be clarified. What remains is to identify the actual subject heading using the subject heading list, and then to check them in the card catalog.

Check the key word Nervous System in the list of subject headings to find what the proper heading is and if there are any related terms that might be useful. What is the proper heading? Are there any related terms that would be useful?

\section{Page 31}

The proper heading is Nervous System. (There are no useful related terms.)

Check under the subject heading Nervous System in the catalog and list the useful volumes.

\section{Page 32}

The books listed under Nervous System seem to deal only with human and vertebrates, while Octopus is an invertebrate. You will notice that the heading Nervous System has several subheadings, such as Addresses, Collected works. What useful books appear under these headings?

Page 33

Nervous System-Invertebrates

Bullock, Structure and Function in the Nervous System of Invertebrates Sci/ QL/925/B8.5 1965.
Lentz, Primitive Nervous Systems Sci/ QL/935/L4.3

Refer to the list on page 30 ; check key words no. 1 and 4 in the red book for their proper headings.

Page 34

The correct form of the key words is:

Mollusks

Invertebrates

Now check these headings in the catalog for useful titles.

Page 35

Mollusks

Physiology of Mollusca Wilbur and Yonge Sci/QL/431/W5.8

Invertebrates

An Introduction to the Behavior of Invertebrates Carthy Sci/QL/364/ C3

Invertebrate Structure and Function Barrington Sci/QL/364/B3

The list of books we have developed provides a substantial list of tertiary and secondary sources useful to this topic. Normally the next step is to sift through the material you have collected and to pick out the important information and bibliographic sources that lead to additional information.

The guided exercise is divided into three sections. Section 1 emphasizes the starting places in library research: texts and/or encyclopedias. In dealing with the encyclopedia, the use of the index and the value of the bibliographies are covered. The card catalog is introduced as a locating device and is later used as a subject index to the library's collection. In the use of the card catalog, the value of the Library of Congress List of Subject Headings is emphasized. In addition, the use of tracings as a method of identifying subject headings is illustrated. The annual review as an important class of literature is stressed and its use to undergraduates is indicated.

Section 2 of the guided exercise deals with the use of the Science Citation Index. In addition to showing how it works and how it may be useful, stu- 
dents are introduced to the library's serials file.

Section 3 is concerned with the use of Biological Abstracts and the skills needed to make effective, efficient use of it. This section begins by typifying a key word index, specifically the key word index of Biological Abstracts. An illustration of how a subject must be analyzed for key words to use in searching Biological Abstracts is included. The organization of the abstracts found through the index is also presented.

It should be noted that the guided exercise is not entirely self-sufficient. There are other materials used in conjunction with the guided exercise. These additional materials are the same as those assigned to the lecture group. The difference being that the students in the exercise group read them when appropriate as they did the exercise while the lecture group students read all the items before coming to the lecture-demonstration.

\section{Evaluation of the Library INSTRUCTION}

While the library instruction was given during the first week of classes and there were several informal opportunities to make use of the instruction for class work, the first real opportunity came with the first examination. This exam consisted of a single essay question on a specific subject related to the general area of the subject being studied. Four examples of the questions used follow.

\section{Four Examples of Library \\ Examination Questions Given to \\ General Biology Students}

\section{The Questions Given for the First Biology Examination}

1. Downtown businessmen are continually concerned with the excrement covering the outsides of their buildings. They, of course, have tried many things to remove the producer of the excrement-the Starling-from urban United States. Discuss the ecology of these increasing Starling populations and the problems involved in controlling them.

2. Populations can be controlled externally by density dependent factors as well as by factors independent of density. Or populations can be controlled from within by factors which are generally density dependent. Go to the literature, which can be found in journals, and select and describe three examples of populations which are controlled by external factors. State the factors, describe the population and their fluctuations with respect to the factors. Do the same for three populations which are controlled by internal factors. You may want to begin your literature search with a secondary source; however, no answer which stops with a secondary source and does not consult the primary literature and document the example as such will be acceptable. When you have accurately described your six examples with the data, you may write a 200 -word summary on the significance of factors which control these populations.

3. Energy flow in the ecosystem: The transformation of solar energy to chemical energy by plants conforms to the laws of thermodynamics:

Solar energy assimilated by plants $=$ Chemical energy of growth of plants (including seeds, exudates, etc.) + Energy of respiration

For herbivores the situation is similar:

Chemical energy eaten by heterotrophs = Chemical energy assimilated by heterotrophs + Chemical energy of faeces produced by heterotrophs

Furthermore:

Chemical energy assimilated by heterotrophs $=$ Chemical energy of growth of heterotrophs (including production of young and excretory products) + Energy of respiration

At each transfer of energy heat is evolved. The end result conforms to the laws of thermodynamics and may be ex- 
pressed: Solar energy entering the system equals heat energy leaving the system. Our interest lies in what happens to the energy after it enters the systems and before it leaves. Refer to an ecological journal (or any other primary source) available in the library, and provide one specific example which illustrates each of the three above equations, i.e., three separate examples. Your examples should include the specific.

4. Document three examples of homology and three examples of anology in the evolution of plants or animals. Is phylogenic classification the best way to do it, or would a more ecological-oriented taxonomy be better? What are the advantages of each?

The students were asked to spend approximately five hours in the library researching the assigned topic. Then, on the basis of the data collected, they were to write a paper, of no more than 1,250 words.

This type of examination was repeated three more times, making a total of four questions for the two terms. The faculty graded these exams. In addition, the librarian evaluated the bibliographies of a randomly selected sample of the students in the two groups. The bibliographies were evaluated on the basis of five criteria: (1) the appropriateness of the references cited to scholarly work in science and biology; (2) the inclusion of the most important secondary sources; (3) the inclusion of a variety (within certain limits) of primary sources; (4) the total number of references; and (5) the format of the bibliography.

The results of the evaluation of the bibliographies which accompanied the papers written for Library Exams 1 and 2 are recorded in Table 1 . The means for the bibilography scores for Exam 1 were 18.60 for the lecture group and 16.34 for the exercise group. A test for significance of difference showed that the difference was not significant. On the second exam the bibliography scores of 20.13 (lecture group) and 21.63 (exercise group) were significantly different at the .20 level of confidence.

TABLE 1

Bibliography Evaluation Results

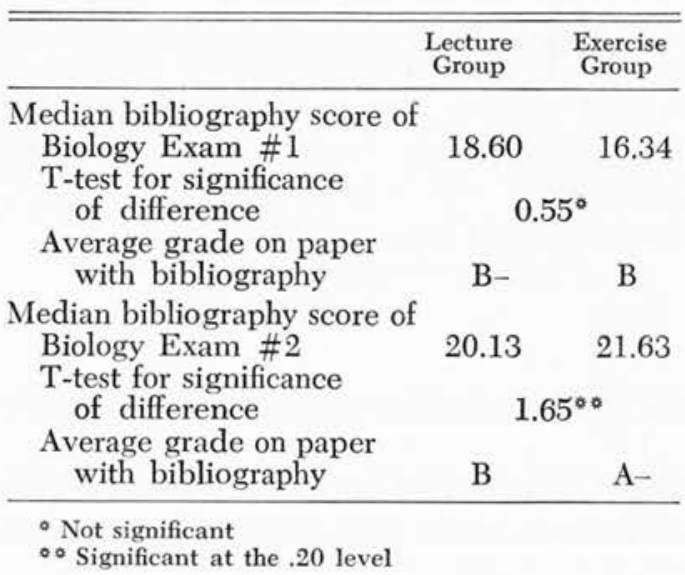

At the beginning of the second term of the course, two library tests were given. The first, "Library Test Number One," was the traditional multiplechoice-matching type, and was constructed by the experimenter. The second exam was titled the "Controlled Association Exam" or "Library Test Number Two." This controlled association technique was first developed by W. S. Verplanck, Department of Psychology, University of Tennessee. ${ }^{6}$ It makes use of a procedure which Edward Green, Institute of Educational Technology, Teachers College of Columbia University, refers to as "controlled association." Briefly, it consists of presenting a list of stimulus words to the student. The student is instructed to respond to a stimulus word by writing down up to four words which he thinks are most meaningfully associated with the stimulus word in the context of the course.

The responses are tabulated and a score is assigned to each of the response words. For those words which are uniquely good associations, a score of 
three points is assigned. For those words which are clearly erroneous associations, a score of zero is assigned. For the vast number of intermediate and ambiguous responses, a score of one is assigned. Clearly, the decision as to what constitutes a uniquely good or a uniquely erroneous response to a given stimulus word is subjective. However, it is probably no more subjective than a determination of any other response where other testing techniques are employed.

The advantages of this procedure are twofold. First, scoring can be automated, thereby yielding the reliability and ease of other objective testing methods such as multiple choice. Second, the universe of responses from which the student may choose what he believes to be correct is not limited, as in multiple choice, which presumably gives some of the advantages of the short answer, essay-type examination.

There are two drawbacks to this procedure. One is that if students are aware of the nature of the examination, they may prepare for it simply by learning a set of associations by rote. In this study the students were unaware of this type of examination before they actually took it. The second disadvantage has to do with the volume of material which is collected from a group of students in one of these testings. The sheer number of responses calls for computer tallying and scoring.

The results of these two tests are included in Table 2 . In summary, the differences that exist are not significant and the test results therefore do not demonstrate the superiority of either instructional method.

In order to get some feedback from students, a student evaluation of their library instruction was given at the end of Term II. In addition, the biology faculty gave a student evaluation of the entire course. This latter evaluation included some questions on the library component of the course.
TABLE 2

Results of Library Tests \#1 and \#2

\begin{tabular}{|c|c|c|}
\hline & $\begin{array}{l}\text { Lecture } \\
\text { Group }\end{array}$ & $\begin{array}{c}\text { Exercise } \\
\text { Group }\end{array}$ \\
\hline \multicolumn{3}{|l|}{ Median score on Library } \\
\hline Test \# 1 & 23.30 & 23.93 \\
\hline Standard deviation & 4.26 & 3.51 \\
\hline $\begin{array}{l}\text { T-test for significance } \\
\text { of difference }\end{array}$ & \multicolumn{2}{|c|}{$0.98^{\circ}$} \\
\hline \multirow{4}{*}{$\begin{array}{l}\text { Median score on Library } \\
\text { Test \#2 } \\
\text { Standard deviation } \\
\text { T-test for significance } \\
\text { of difference }\end{array}$} & & \\
\hline & 48.30 & 46.27 \\
\hline & 19.23 & 13.86 \\
\hline & \multicolumn{2}{|c|}{$0.73^{\circ}$} \\
\hline
\end{tabular}

- Not significant.

On the library's evaluation form students were asked to rate the library instruction which they had received. Two of the questions provide the most useful information; this is presented in Table 3 . This table gives the percentages of students who checked the various categories.

The student evaluation results (Table 3 ) indicate that the students' opinions of their library instruction did not differ significantly. Also, their opinions as to what they learned do not differ between the two groups. A significant difference does appear when asked whether the students had personal help from the librarian (Table 3 ). Of the group that had the guided exercise, only 43 percent had personal help, while 65 percent of the lecture group had such help. There are two possible explanations. One, the exercise group may not have needed as much help; however, the results of the students' opinion of what they learned conflicts with that reason. Second, the lack of extended (two hours) contact with the librarian during the lecture may have inhibited the guided exercise students from asking questions. Which mechanism is operating here remains an unanswered question but is one which deserves serious investigation.

Table 4 presents a portion of the results of a much larger evaluation which 
TABLE 3

Results of Students' Evaluation of Their Library Instruction

\begin{tabular}{lcc}
\hline \hline $\begin{array}{c}\text { Degree to Which This Method } \\
\text { of Instruction Was Helpful }\end{array}$ & $\begin{array}{c}\text { Lecture } \\
\text { Group }\end{array}$ & $\begin{array}{c}\text { Exercise } \\
\text { Group }\end{array}$ \\
\hline Very helpful & $12 \%$ & $16 \%$ \\
Helpful & 66 & 54 \\
Not very helpful & 20 & 28 \\
Useless & 2 & 3 \\
Did you receive personal help from the & & \\
$\quad$ librarian in seeking out literature & & \\
$\quad$ for your test questions? & 65 & 43 \\
Yes & 35 & 57 \\
No & & \\
\hline
\end{tabular}

TABLE 4

Results of a Portion of the Biology Evaluation Which Is RELATED to LibraRy INSTRUCTION

\begin{tabular}{lcc}
\hline \hline \multicolumn{1}{c}{ Statements Presented to Students } & $\begin{array}{c}\text { Total } \\
\text { Number } \\
\text { Responses } \\
\text { per } \\
\text { Statement }\end{array}$ & $\begin{array}{c}\text { Percentage } \\
\text { of Total } \\
\text { Responses } \\
\text { per Item }\end{array}$ \\
\hline I. In the Biology course, the library was ... & 96 & \\
A. overemphasized & 29 & $30 \%$ \\
B. appropriately emphasized & 66 & 69 \\
C. not emphasized enough & 1 & 1 \\
II. Comment briefly on the library & 87 & \\
examinations as an educational device & 80 & 92 \\
A. valuable & 7 & 8 \\
B. not valuable & 98 & \\
III. Examinations and quizzes other than the library type exams & 45 & 46 \\
A. My lab section ... & 53 & 54 \\
1. used them & 37 & 49 \\
B. didn't use them & 18 & 51 \\
1. should have used them more & 19 & 48 \\
C. . should not have used them more & 42 & 26 \\
1. learned & 20 & 26 \\
2. the same & 11 & \\
3. more & 11 & 93 \\
D. I worked harder for ... & 42 & 9 \\
1. library examinations & 39 & 3 \\
2. other hour exams & 3 & 9 \\
\hline
\end{tabular}

the biology faculty carried out covering the entire Biology 11 and 12 course. The portion included here covers the students' responses to questions about their opinions of the examinations.

The students' overall evaluation of the library component of the course as revealed in the second student evaluation was very positive. This enthusiasm is quite encouraging since they also felt that the library examinations required more work then other hour exams.

\section{Conclusions}

It is expected that a carefully designed instructional program which takes into account a clear set of objectives and the structure and objectives of the course in which the program is used should be a superior method in comparison with the less original, more straightforward lecture. However, the results of the experiment do not provide cause for selecting the exercise over the lec- 
ture. Of the four different sets of evaluation results, three show no difference of significance, while for the one that did, the level of significance was low (.20 level). Table 5 presents the T-test for significance of difference calculated from the four sets of data.

TABLE 5

T-Test for Significance of Difference

\begin{tabular}{|c|c|c|}
\hline Type of Evaluation & $\begin{array}{c}\text { T-Test } \\
\text { Calculation }\end{array}$ & Significance \\
\hline \multicolumn{3}{|l|}{ Bibliography scores from } \\
\hline $\begin{array}{l}\text { Biology Exam \#1 } \\
\text { (Table 3) }\end{array}$ & 0.55 & None \\
\hline \multicolumn{3}{|l|}{ Bibliography scores from } \\
\hline $\begin{array}{l}\text { Biology Exam \#2 } \\
\text { (Table } 3 \text { ) }\end{array}$ & 1.65 & .20 level \\
\hline Library test \#1 (Table 4 ) & 0.98 & None \\
\hline Library test \#2 (Table 4 ) & 0.73 & None \\
\hline
\end{tabular}

The students' evaluation of their library instruction and of the library aspects of the course also provides no basis for choosing one method over the other. As was discussed earlier, the lecture group did ask for more individual help than did the exercise group. However, because there may be factors at work other than the superior skills of the exercise group, it is not possible to use the student evaluation results to support any claims about the superiority of one method over the other.

One must conclude, therefore, that the instructional method is superior neither in its ability to teach the use of the library, nor in its ability to promote an appreciative attitude toward the library. Thus, any decision as to which method to use in subsequent classes must be based on other criteria.

The faculty and the library staff have continued to use the guided exercises in teaching the use of the library to general biology students. Once it was established that the exercise would do as adequate a job as the lecture, we began to look at other factors which might rec- ommend one method over the other. In the following paragraphs, the reasons we have continued to use the exercise are outlined. In addition, some improvements in the program that were implemented in later years are discussed.

The criteria used in making a judgment as to which method to use included: (1) the time needed to prepare the materials necessary for teaching under the two programs; (2) the student time spent in the instructional program; (3) flexibility of the two methods; and (4) the potential burden caused by the guided exercise's reliance upon actual use of the library during the instruction.

The time spent in preparing the exercise and the lecture, because of their great similarity, was essentially the same. Therefore, initial investment of time is the same. The long-term investment of time, however, would be greater for the lecture method. The exercise, once prepared, needs only minor revisions. Related to this is the flexibility which the program permits: Any time an individual student or group of students needs the instruction, the guided exercises are available. Furthermore, a student can proceed at his own pace. Because of its division into three parts, it can be done in stages so that the entire four or five hours needed for completion does not need to be invested at one time. Furthermore, if a student needs instruction on only one aspect, he need do only the appropriate section of the exercise.

The amount of time students spend during the instruction is obviously greater for the exercise method. This is, unfortunately, inherent in the nature of the exercise, and little can be done except for some internal improvement in the program.

Finally, the question of whether the exercise burdens the library collection, especially key items that every student uses, must be faced squarely. Is the library willing to have certain items used 
as heavily as is required for the use of the exercises? There are certain steps that can be taken to alleviate the problem. These steps include: (1) When large groups of students are involved, give the exercise to part of the group at different times; (2) have several exercises in widely different areas; (3) purchase multiple copies of the most heavily used items. These measures will not solve the problem; they will only reduce its seriousness.

\section{Improving the Instructional Plan}

In order to make the exercise method of instruction more efficient and useful, certain necessary changes were carried out when the program was repeated. These changes included:

1. Additional guided exercises in other subject areas were written. These new exercises were on: "internal factors in population size control" and "chromosome mapping using mitotic recombination." This variety, as suggested earlier, did help to relieve much of the crowding and heavy use of some materials. This did not, however, prevent heavy use of the basic tools-encyclopedias, dictionaries, the card catalog, and periodical indexes.
2. The assignment of the exercise was spread out over a two-week period. Because the exercise was considered a laboratory assignment it could be alternated with another laboratory assignment. In this way one-half the class did the library exercise one week while the other half of the class did another laboratory assignment. The next week the assignments were reversed.

3. One of the major failures of the initial experiment was the faculty's ignorance as to the best sources for the examination questions. In order to correct this problem and to help insure that only questions which could reasonably be answered on the basis of the library's holdings were used, all questions were searched by the library staff prior to giving them to the students. This search made possible a more detailed evaluation of the bibliographies associated with the examination questions.

It is significant that a study of the correlation between the grades received from the faculty on the library examinations and the bibliography scores received from the librarian revealed greater correlation in the second year than in the first. ${ }^{7}$

\section{REFERENCES}

1. Luella Snyder, The Second Kind of Knowledge, p.3.

2. Daniel Bell, "Reforming General Education," in Improving College Teaching, p.351.

3. P. B. Knapp, The Monteith College Library Experiment, p.11 (Citing Proposal to the United States Office of Education, p.1-2, by Patricia B. Knapp).

4. Snyder, The Second Kind, p.6-7; Knapp, ibid., p.39-40.

5. Snyder, ibid., p.7.

6. Unfortunately, nothing has been published on this technique. This author's information comes from communication with Louis Wilcox of the Earlham Biology Department. Wilcox has had contact with Edward Green of Columbia University. The computer programs used to score this exam were revised from those used at Columbia University.

7. The correlation figures were as follows: original experiment -.16 (lecture group), and .53 (exercise group); second-year class sections $.80, .80, .87, .82$ (all used exercise). 